\title{
Nas malhas da poesia: oficina da leitura e criação
}

\author{
In meses os poetry: workshop of Reading and creation
}

\author{
Rosa Maria Cuba Riche \\ Instituto de Aplicação Fernando Rodrigues da Silveira - Cap UERJ - Rio de Janeiro - Brasil
}

\begin{abstract}
Resumo: Como e por que trabalhar poesia na sala de aula é o que se pretende abordar neste trabalho. A sensibilização para a linguagem poética, suas características estruturais e um pequeno repertório teórico que sustenta a reflexão sobre o fazer poético vêm sendo abordados ao longo da atividade acadêmica em forma de Oficinas de Leitura e Produção. Os grupos que vivenciaram a metodologia dessas oficinas são estudantes do Ensino Fundamental I e II, estagiários de Letras do Instituto de Aplicação da UERJ, profissionais de diferentes áreas da disciplina Oficina de Poesia do curso de Especialização em Literatura Infantil e Juvenil da UFF, além de professores que frequentaram minicursos em congressos da área. As oficinas de poesia têm se mostrado eficazes como possibilidade de aproximar do gênero lírico diferentes tipos e faixas etárias de leitores, permitindo-Ihes manipular o estrato linguístico de forma criativa e, principalmente em relação aos professores da educação básica, vivenciar atividades que podem enriquecer a prática docente. Os resultados dessas oficinas podem ser mensurados pelo maior interesse dos estudantes em ler, compreender e produzir poemas e a participação entusiasmada dos professores que inseriram a metodologia da oficina em suas práticas docentes. O repertório ficcional é amplo e varia de acordo com o público participante e a experiência do leitor. Já o repertório teórico apoia-se principalmente em: CANDIDO (1986; 1989; 2004); CÍCERO (2007); SOARES (1989); CARA (1986); MORICONI (2002); MOISÉS (2012); SECCHIN (2018) dentre outros.
\end{abstract}

Palavras-chave: Oficina. Leitura. Produção textual. Poesia.

Abstract: This paper intends to address how and why to work with poetry in the classroom. Awareness of poetic language, its structural characteristic and a brief theoretical framework that give support to reflections on ways of doing poetry has been worked on throughout academic activity in the form of Reading and Production Workshops. Groups that have experienced the methodology of those workshops comprise students from primary and middle schools and undergraduate students of the Lyrics Course in the Institute of Application at UERJ as well as professionals from different areas of knowledge in the subject Poetry Workshop from the specialization course in Children and Youth Literature and teachers who attended mini courses in congress in the area. The poetry workshops have proved to be effective as a possibility to bring different types and age groups of readers closer to the lyric genre, allowing them to manipulate the linguistic stratum in a creative way, especially basic education teachers, who have the chance to experience activities that can improve teaching practice. The results of these workshops can be measured by students' greater interest in reading, understanding and producing poems and the enthusiastic participation of the teachers who adopted the workshop methodology in their teaching practices. The fictional repertoire is broad and varies according to the participating audience and reader's experience. The theoretical framework is based mainly on: CANDIDO (1986; 1989; 2004); CíCERO (2007); SOARES (1989); CARA (1986); MORICONI (2002); MOISÉS (2012); SECCHIN (2018) among others.

Key words: Workshop. Reading. Textual production. Poetry 


\section{Introdução}

Do nascimento à idade adulta, a poesia está presente na vida do homem. Nas cantigas de ninar, adoçadas pela voz e o cheiro do leite materno que embalam o recém-nascido, nos versos das cantigas de roda, nas brincadeiras de rimar tão ao agrado das crianças, nas músicas cantadas no jardim de infância, acompanhadas pelos movimentos do corpo, a musicalidade e o ritmo da poesia estão presentes. Ela adentra os primeiros anos escolares até transformarse em texto de análise das provas de acesso à universidade.

No meio desse percurso, a poesia se esconde nas páginas dos diários, circula nos bilhetes ao primeiro amor, mas nem sempre sua leitura permanece prazerosa, quando precisa ser dissecada nas avaliações escolares. Muitas vezes esse desencantamento se dá pela forma como ela passa a ser tratada, não mais como uma leitura que emociona e sensibiliza o leitor, mas como um emaranhado de termos que aquele estudante que ingressou na escola cheio de imaginação é obrigado a decorar para etiquetar versos, rimas, figuras de linguagem, sintaxe, estilo, época e outros elementos que o poema possa conter.

O que se pode fazer para que a experiência afetiva, espiritual e artística que a poesia pode proporcionar seja resgatada e esteja presente na escola e em outros espaços menos formais onde a educação estética também acontece? A partir dessa indagação pretende-se aqui refletir sobre a construção de metodologias que apontem caminhos e estratégias e que contribuam para construir saberes que vão da compressão do texto ao estímulo à criação.

Parte-se do pressuposto de que a adolescência e os primeiros anos da juventude compreendem o período do autoconhecimento, da descoberta do mundo, da imaginação fértil e do espírito crítico mais aguçado. Esse é o momento de vivenciar experiências que certamente irão marcar a vida do indivíduo para sempre. As inquietações típicas dessa fase são a matéria prima de muitos poetas que escrevem e se inscrevem em seus poemas também buscando se encontrar. E por que não a escola proporcionar esse prazer estético através da prática da leitura de poemas na sala de aula, aproveitando esse período de vida dos estudantes? Tudo depende da postura diante do texto poético, de acreditar que, antes de regras, vale sensibilizar e despertar o desejo de ler através do contato com uma ampla variedade de tipos, gêneros e estilos diversificados.

A leitura em voz alta, a entonação de cada palavra, a pontuação, a marcação do ritmo, a leitura em forma de jogral, dependendo do estilo, colaboram para a compreensão do poema que vai se descortinando aos poucos aos olhos do leitor. Há muitos caminhos a percorrer para se alcançar o prazer estético, mas nenhum deles passa pela visão única ou pela imposição de sentidos. Assim vale a descoberta de novos sentidos, a tentativa de deixar vir à tona sensações, intuições, opiniões divergentes, atitudes que favorecem à construção de um saber individual e coletivo. Afinal a compreensão de qualquer gênero textual exige a relativização de juízos e de opiniões, e a escola deve ser esse espaço democrático para a realização de atividades que fomentem a troca de saberes.

\section{Oficina de poesia: sugestões de metodologias}

De acordo com o dicionário etimológico, a palavra Oficina tem origem em Ofício:

1. Ofício tem origem em 'officium', que, por sua vez, tem ligação com 'opifex' (formado por 'opus', obra, e fex, sufixo ligado ao verbo 'facere', que está na origem de fazer). Opifex' era aquele que fazia a obra, 'officium' era o trabalho do "opifex".

2. Oficina tem origem em 'officina' - lugar de trabalho do 'opifex". (LOURO, 2020)

O termo oficina tem, portanto, origem em ofício, que tem ligação com opifex, aquele que fazia obra, associado ao fazer (facere), ao experimento, à criação e às tentativas de erro e de acerto que a atividade implica. Remonta ao fazer com as mãos, ao saber da experiência de que nos fala Walter Benjamin, que se perdeu na Era da Reprodutibilidade técnica. Inclui também a ideia de processo de criação, que os artesãos experimentam ao utilizar os mais diferentes 
tipos de materiais, inclusive a palavra. Vale relembrar os poetas parnasianos burilando a forma como nesses versos do poema Profissão de fé, de Olavo Bilac:

Quero que a estrofe
cristalina,
Dobrada ao jeito
Do ourives, saia da oficina
Sem um defeito. (2001,
p.14-15)

Uma vez esclarecidas as acepções de oficina e a sua ligação com a criação, há que se refletir sobre o terceiro conceito que completa o título desse artigo, poesia. Um conceito bem amplo, que não constitui um saber universal. Isso fica claro ao se fazer uma consulta em sites de busca na Internet e se constatar a grande quantidade de respostas variadas para 0 termo: aproximadamente 184.000 .000 resultados $(0,45$ em segundos). Os conceitos e definições vão da acepção dicionarizada à tipologia variada, às definições subjetivas, dependendo dos contextos históricos e culturais em que a poesia foi gestada. De acordo com os estudos de Carlos Perrone Moisés, desde a Poética de Aristóteles (século IV a.C) até os tratados modernos que tentam definir conceitos, classificações, princípios gerais, todos válidos, percebe-se uma gama variada de acepções que percorrem a cronologia histórica, mas não se pretende aqui discorrer sobre elas. (MOISÉS, 2012, p. 10)

A práxis pedagógica, no contato com os mais diferentes públicos que vão do estudante da educação básica ao pós-graduando e ao professor, aponta também para uma gama infindável e variada de conceitos e definições. Uma pequena amostra pode ser colhida nas aulas e ou oficinas ministradas a estudantes e profissionais dos diferentes níveis de escolaridade.

Parte-se do princípio de que a experiência com a poesia está presente no cotidiano, antecede o ingresso na educação sistematizada e continua ao longo do período acadêmico. A metodologia proposta aqui pretende resgatar o prazer da experimentação que vai da leitura e do contato com o gênero, em sua gama variada de tipos, à produção individual de poemas.
Antes de passar às etapas do processo, há que se esclarecer que não se trata de uma receita de procedimentos instrucionais de como ler, entender e escrever poesias, mas de atividades organizadas de modo a sensibilizar e a despertar o prazer estético que o gênero pode proporcionar. O planejamento delas implica em uma pesquisa de textos poéticos, informativos e teóricos que instrumentem melhor o orientador, seja ele professor ou agente cultural, que munido deles possa esclarecer dúvidas que surgem por parte dos participantes e que contribuem para construção de um conhecimento coletivo.

Sendo assim, é preciso preparar essas atividades de acordo com o público alvo. Inicialmente sugere-se: a) selecionar e imprimir poemas de diferentes tipos e autores para serem distribuídos aos participantes no momento inicial da leitura individual; b) selecionar um ou mais para o trabalho coletivo de reconstrução de um poema; c) providenciar os materiais para serem distribuídos aos participantes, como folhas de papel branco, colorido e celofane e lápis de cor para ilustrar a produção nos anos iniciais. Feito isso, parte-se para a realização das atividades.

É importante ressaltar que as sugestões que se seguem já foram testadas com resultados positivos nos diferentes níveis de escolaridade, inclusive nos cursos de pós-graduação. Privilegia-se aqui o primeiro e o segundo segmento da educação básica, mas elas podem ser estendidas aos estudantes do Ensino Médio com as devidas adaptações para esse público.

\section{Sensibilização}

Nesse momento inicial, o participante entra em contato com os mais variados tipos de poemas. Para isso o orientador já os selecionou previamente, levando em consideração a faixa etária, a maturidade, o nível de escolaridade, o contexto e os objetivos a serem alcançados com a proposta. Seguem as sugestões:

A) Distribuir aleatoriamente os poemas para uma leitura individual silenciosa. Ao longo desse texto, há um elenco de poemas já utilizados em oficinas realizadas com turmas da educação básica. 
B) Leitura oral individual de cada poema, enfatizando a entonação e a pontuação. Chamar a atenção para o ritmo e a musicalidade, advindos da escolha vocabular. Caso alguma palavra ou figura de linguagem não seja compreendida, o que acontece com os leitores menos experientes, o orientador deve explicá-la ao grupo. Ainda não é o momento para análises mais profundas nesse contato inicial. A troca de poemas entre os participantes é bem-vinda bem como o diálogo entre eles e o orientador e os comentários que enriquecem e facilitam a compreensão global dos textos.

Nessa etapa, sugere-se apresentar o poema Trem de ferro, de Manuel Bandeira, que pode ser lido em voz alta em forma de jogral. É possível explorar o ritmo, as rimas, a musicalidade, bem como as aliterações e outros recursos da linguagem de forma assistemática. Nos anos iniciais da educação básica, os estudantes gostam de acompanhar a leitura batendo o pé no chão, o que facilita a percepção do ritmo. O orientador pode aproveitar esse momento para chamar a atenção para esses elementos característicos do gênero.

Poesia é ...

Depois da sensibilização, o orientador solicita aos participantes que leiam algumas definições de poesia previamente selecionadas e completem a frase "Poesia é.." com as concepções pessoais do que é poesia. O objetivo é acompanhar as diferentes definições que o mesmo participante irá redigir ao final das atividades que podem ser apresentadas oralmente. Seguem alguns exemplos, mas é interessante selecionar outros:

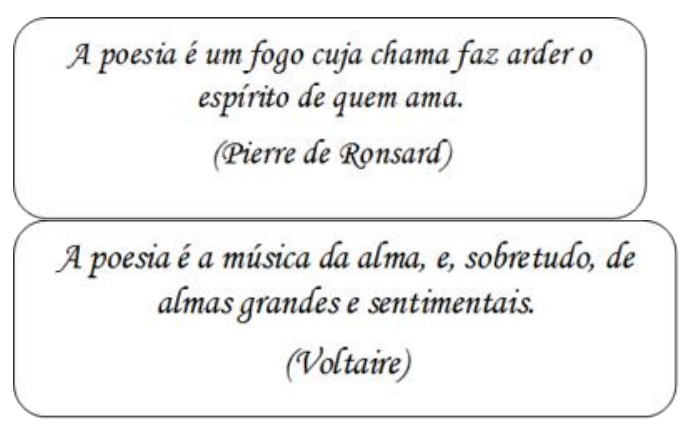

\section{Análise de poemas}

Depois do contato com diferentes tipos de poemas, parte-se para a escolha de dois ou três deles para serem lidos e analisados por toda a turma. Sugere-se aqui, à guisa de exemplo, Leilão de jardim, de Cecília Meireles (1990 p.16;) e O adolescente, de Mário Quintana (2003, p.8-9). Ver as referências completas ao final deste artigo.

Inicia-se com a leitura oral compartilhada. $\mathrm{O}$ orientador vai chamando a atenção dos participantes para as características do gênero presentes no poema ressaltando: o ritmo, as rimas se houver, a musicalidade, o sensorialismo, a antidiscursividade, a ilogicidade, o ludismo da linguagem que promovem efeitos de sentidos e geram o prazer estético.

A guisa de exemplificação, em Leilão de jardim, a escolha vocabular, a seleção e a combinação das palavras que criam as rimas (flores/cores; passarinhos/ninhos) são responsáveis pelo ritmo e a musicalidade do poema. O sensorialismo, por sua vez, é estimulado pelas cores das flores, dos pássaros, dos ovos e dos insetos, como se observa na primeira estrofe:

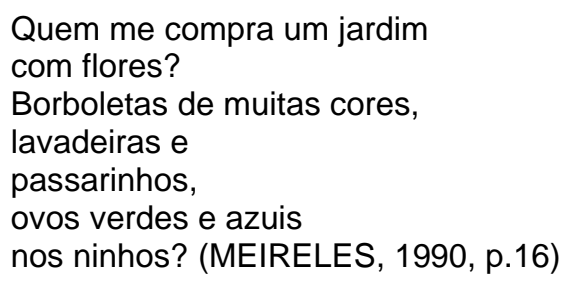

Já a ilogicidade está presente nos versos da segunda estrofe:

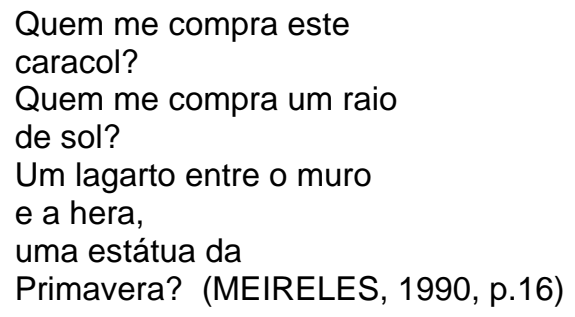

Quem me compra este caracol?

Quem me compra um raio

de sol?

Um lagarto entre o muro

e a hera,

uma estátua da

Primavera? (MEIRELES, 1990, p.16)

Em $O$ adolescente, de Mario Quintana, as repetições de palavras (medo/medo); de fonemas /E/ (bela/gela); /F/ (fascinante/fremente; em frente/farejando); /V/ (vida/nova); /S/ (estátua/súbita) e de expressões (a vida é nova.../ a vida é nova) criam rimas internas, imprimem musicalidade e ritmo ao poema. O tamanho dos versos ora longos, ora curtos, 
o uso dos sinais de pontuação são recursos da linguagem que contribuem para o ritmo. Assim também as comparações e as metáforas (jovem felino/ farejando o vento; as folhas contam-te um segredo; a vida anda nua/vestida apenas com o teu desejo) devem ser igualmente sinalizadas durante a leitura, lembrando que não se trata de uma análise exaustiva.

\section{O Adolescente}

A vida é tão bela que chega a dar medo. Não o medo que paralisa e gela, estátua súbita,

mas

esse medo fascinante e fremente de curiosidade que faz

o jovem felino seguir em frente farejando o vento

ao sair, pela primeira vez, da gruta.

Medo que ofusca: luz!

Cumplicentemente

as folhas contam-te um segredo

velho como o mundo:

Adolescente, olha! A vida é nova...

A vida é nova e anda nua

- vestida apenas com o teu desejo! (QUINTANA, 2003, p.8-9)

Vale esclarecer ainda para o grupo a presença do "eu lírico" ou "eu- poético", a voz que se manifesta no poema que não pode ser confundida com o autor.

\section{Reinventando o poema}

O poema é, portanto, o resultado da seleção e da combinação de palavras que o poeta organiza a seu modo no momento da criação, gerando efeitos de sentidos, provocando reações diversas nos leitores no momento da recepção.

O objetivo dessa etapa é convidar o participante a reorganizar o poema, ou seja, com a seleção de palavras do autor fazer uma outra combinação, criando um novo poema. Nem todas as palavras precisam ser empregadas no poema a ser criado. É o momento de manusear as palavras, criar novas combinações, gerar imagens e produzir outros sentidos.

Para facilitar, sugere-se que os poemas sejam escritos em letras de tamanho maior para que as palavras possam ser recortadas, organizadas e coladas em outro papel. Os estudantes apreciam muito essa atividade. Segue um exemplo criado por uma estudante do $7^{\circ}$ ano, a partir do poema $O$ adolescente, de Mário Quintana:

\section{A curiosidade}

A vida não é tão bela,

Chega, paralisa

E gela. Mas esse medo é fascinante,

Faz o jovem seguir em frente.

Ofusca o medo,

Adolescente!

A vida é um segredo

Velho como o mundo

E anda nua

Vestida apenas com sonhos.

Maria Fernanda Cerqueira Carvalho (2019)

\section{Letra de música também é poesia?}

Essa é uma questão que aparece em algumas oficinas, gera dúvidas e curiosidade e por isso é bom refletir sobre a distinção entre poesia e letra de canção. A leitura oral compartilhada e comentada de cada parágrafo do texto de Antônio Cícero ajuda a pensar sobre o tema:

Letra de canção e poesia

Como escrevo poemas e letras de canções, frequentemente perguntam-me se acho que as letras de canções são poemas. A expressão "letra de canção" já indica de que modo essa questão deve ser entendida, pois a palavra "letra" remete à escrita. O que se quer saber é se a letra, separada da canção, constitui um poema escrito.

"Letra de canção é poema?" Essa formulação é inadequada. Desde que as vanguardas mostraram que não se pode determinar a priori quais são as formas lícitas para a poesia, qualquer coisa pode ser um poema. Se um poeta escreve letras soltas na página e diz que é um poema, quem provará o contrário?

Neste ponto, parece-me inevitável introduzir um juízo de valor. A verdadeira questão parece ser se uma letra de canção é um bom poema. Entretanto, mesmo esta última pergunta ainda não é suficientemente precisa, pois pode estar a indagar duas coisas distintas: 1) Se uma letra de canção é necessariamente um bom poema; e 2) Se uma letra de canção é possivelmente um bom poema.

Quanto à primeira pergunta, é evidente que deve ter uma resposta negativa. Nenhum poema é necessariamente um bom poema; nenhum texto é necessariamente um bom poema; logo, nenhuma letra é necessariamente um bom poema. Mas talvez o que se deva perguntar é se uma boa 
letra é necessariamente um bom poema. Ora, também a essa pergunta a resposta é negativa. Quem já não teve a experiência, em relação a uma letra de canção, de se emocionar com ela ao escutá-la cantada e depois considerá-la insípida, ao lê-la no papel, sem acompanhamento musical?

Não é difícil entender a razão disso. Um poema [...] tem o seu fim em si próprio. Quando o julgamos bom ou ruim, estamos a considerá-lo independentemente do fato de que, além de ser um poema, ele tenha qualquer utilidade. $O$ poema se realiza quando é lido: e ele pode ser lido em voz baixa, interna, aural. Já uma letra de canção [...] não tem o seu fim em si própria. Para que a julguemos boa, é necessário e suficiente que ela contribua para que a obra líteromusical de que faz parte seja boa. Em outras palavras, se uma letra de canção servir para fazer uma boa canção, ela é boa, ainda que seja ilegível. E a letra pode ser ilegível porque para se estruturar, para adquirir determinado colorido, para ter os sons ou as palavras certas enfatizadas, ela depende da melodia, da harmonia, do ritmo, do tom da música à qual se encontra associada.

Mas isso ainda não é tudo. A letra se realiza na canção, mas a canção só se realiza plenamente quando interpretada, isto é, quando cantada e ouvida. Ora, como Luiz Tatit mostra em seu belíssimo livro $O$ Cancionista, "no mundo dos cancionistas não importa tanto o que é dito, mas a maneira de o dizer, e a maneira é essencialmente melódica". Será sem dúvida por isso que podemos perfeitamente apreciar cantores a cantar canções em línguas que não entendemos. Em suma, uma boa letra de canção não é necessariamente um bom poema.

A resposta para a segunda pergunta, por outro lado - se uma letra de canção é possivelmente um bom poema - é evidentemente positiva. Os poemas líricos da Grécia antiga e dos provençais eram letras de canções. Perderam-se as músicas que os acompanhavam, de modo que só os conhecemos na forma escrita. Ora, muitos deles são considerados grandes poemas; alguns são enumerados entre os maiores que já foram feitos. Além disso, nada impede que um bom poema, quando musicado, se torne uma boa letra de canção.

Para dizer a verdade, o que nos intriga hoje é que haja tantos grandes poemas entre as letras gregas e provençais e tão poucos entre as modernas. Entretanto, a leitura do livro Letra Só, de Caetano Veloso - que contém tantos grandes poemas que são também letras de canções -, fez-me pensar melhor sobre essa questão. Para o punhado de poemas de Safo, por exemplo, que nos chegaram, dentre os quais meia dúzia de obras-primas, quantos milhares de letras de canções não tiveram que ser escritos e esquecidos na Grécia antiga? (CÍCERO, 2020)

O texto merece uma reflexão, mais indaga do que responde e provoca a discussão sobre o tema, o que é muito saudável para o aprendizado. O autor sinaliza que o poema se realiza por si só, diferentemente da letra da canção que precisa ser cantada e interpretada. Nem toda letra de música é um bom poema; são gêneros distintos. Outros autores também participam desse debate. Ítalo Moriconi, por exemplo, afirma que a poesia está nas letras da música popular, no cordel nordestino, no Rock dos anos 80, no hip hop dos anos 90. Para ele, "No Brasil, depois da Bossa Nova e da MPB, a própria canção popular tem se alimentado da literatura". (2002, p.12) E complementa dizendo: "Na verdade, essa indistinção e até certo ponto fusão conceitual entre poesia e canção tem uma longa história em nossa cultura literária". (2002, p.13). Há os que defendem a letra de música como poesia, sem ressalvas, e outros que defendem que a letra de música jamais se sustenta como poesia autêntica de livro. É uma questão aberta ainda à discussão.

Para complementar a reflexão, pode-se associar a ela a origem do Gênero Lírico, mas antes é interessante retomar o que pensam os estudiosos sobre a teoria dos gêneros, à guisa de esclarecimento.

Angélica Soares, em seus estudos sobre as teorias dos gêneros, afirma que: "nunca se deve descrever um gênero aprioristicamente, sem considerar os modos concretos de recepção dos textos" (SOARES, 1989, p.21). Salienta também que "os traços dos gêneros estão em constante transformação; portanto, no ato da leitura, nos devemos conduzir abertamente pelas mudanças e não por características fixas". (SOARES,1989, p.21). Mas deve-se levar em conta os traços que vêm caracterizando historicamente os gêneros. E conclui alertando que "a teoria de gêneros é vista como meio auxiliar, que entre outros, nos leva ao conhecimento do 
literário, mas nunca deve ser usada para a valorização e julgamento da obra". (SOARES,1989, p.22).

Nesse sentido, vale retomar novamente à Antiguidade Clássica e lembrar que:

enquanto a epopeia destinava-se a cantar o coletivo, a unidade da pólis, outro tipo de composição, naquela época acompanhada pela flauta ou pela lira, surgia voltada para a expressão de sentimentos mais individualizados, como as cantigas de ninar, os lamentos pela morte de alguém, os cantares de amor. Eram os cantos líricos que (mesmo ligados a aspectos da vida comunitária: o "lirismo coral"), já em suas origens, vinham marcados pela emoção, pela musicalidade e pela eliminação do distanciamento entre o eu poético e o objeto cantado. (SOARES, 1989, p.24).

Com o passar do tempo, essa composição deixou de ser acompanhada pelos instrumentos, passou da forma cantada para a escrita, mas conservou os recursos que aproximam música e palavra. Assim permaneceram as repetições de sons, de sílabas, de palavras responsáveis pela criação das rimas, do ritmo, da musicalidade e de toda tensão criada entre os sons e o sentido das palavras. Uma vez pontuadas essas questões do gênero, passa-se à análise de poemas.

\section{Análise de poemas}

Depois do contato com poemas, da recriação a partir de um deles, é o momento de escolher um para ser analisado pelos participantes, lembrando que a escolha sempre deve levar em conta o público alvo e o contexto. As características do gênero que foram apontadas no momento inicial serão retomadas aqui.

Parte-se do pressuposto que cada poema requer uma abordagem adequada à sua natureza, mas sempre apoiada em instrumental teórico comum. Lembrando Antonio Candido, há que se considerar:

que os significados são complexos e oscilantes (...) que o texto é uma espécie de fórmula, onde o autor combina consciente ou inconscientemente elementos de vários tipos. Por isso, na medida em que se estruturam(..) esses elementos só podem ser considerados externos ou internos por facilidade de expressão. (CANDIDO,1986, p.5)
Desse modo, a abordagem, também segundo a metodologia de Candido, inicia-se com a compressão do significado, a interpretação do tema e a tonalidade do discurso, a ordem sintática e os recursos da linguagem figurada. Exemplificando melhor como esses elementos se estruturam, veja-se o poema de Cecília Meireles:

\section{RÔMULO REMA}

Rômulo rema no rio.

A romã dorme no ramo,

a romã rubra. (E o céu.)

O remo abre o rio.

$\mathrm{O}$ rio murmura.

A romã rubra dorme cheia de rubis. (E o céu.)

Rômulo rema no rio.

Abre-se a romã.

Abre-se a manhã.

Rolam rubis rubros do céu.

No rio,

Rômulo rema.

(MEIRELES, 1990, p. 27)

Através da leitura oral com entonação, percebe-se a repetição dos fonemas $/ R /$ e $/ M /$, que contribuem para a significação geral do tema, alguém que rema no rio em um dia ensolarado antes do amanhecer, corta o rio com seu remo e permanece remando depois que o dia amanhece. $O$ som provocado pela repetição desses fonemas lembra o marulhar das águas do rio. Nesse cenário, a romã se abre no momento em que o dia amanhece.

O tom do discurso se mantém em todo o poema com a ordem expositiva clara e direta: "Rômulo rema no rio./A romã dorme no ramo,/a romã rubra. ( $E$ o céu.). No entanto, no seu todo, o poema é figurado, mesmo privilegiando a ordem direta: "A romã dorme no ramo", "O rio murmura", com exceção dos versos "Abre-se a romã./Abre-se a manhã" que marcam uma quebra de expectativa do leitor com o nascimento do dia.

Interessante é observar também a inversão da ordem sintática do primeiro verso, "Rômulo rema no 
rio", no último, "No rio, Rômulo rema". No primeiro verso, o sujeito da ação vem antes da ação e do lugar, apresentando a cena que se descortina nas estrofes seguintes. Já no último, o cenário/rio antecede o sujeito Rômulo, dando ideia de continuidade da ação, de permanência no rio, mesmo depois do nascimento do dia. Configura-se aqui o jogo da linguagem nessa inversão. Observa-se também a expressão "E o céu.", que vem entre parêntese, chamando a atenção do leitor para a chegada da manhã que virá nos versos seguintes que culminam com a romã que se abre madura com os rubis, metáfora dos caroços que caem, "Rolam rubis rubros do céu". Assinala-se aqui a ilogicidade do discurso resultante das metáforas, da linguagem conotativa que configuram o espaço poético ligado à passagem do tempo da madrugada para a manhã.

Outro aspecto a analisar é a estrutura do poema, o número de estrofes (8) e a distribuição dos versos (13). A primeira introduz a cena, "Rômulo rema no rio". Da segunda à quinta, descortina-se o cenário, o dia ainda dorme assim como a romã e o céu. $\mathrm{Na}$ sexta estrofe, a repetição do verbo de ação abrir anuncia a chegada do dia, "Abre-se a romã./Abre-se a manhã"; e já madura, com a chegada do dia, a romã se abre e "Rolam rubis do céu". A distribuição dos versos nas estrofes aponta para a introdução de cada elemento na cena: Rômulo e o rio ( $1^{\underline{a}}$ ); A romã e o céu ( $2^{\mathrm{a}}$ ); o remo e o rio ( $3^{\mathrm{a}}$ ); a romã ( $4^{\mathrm{a}}$ ); a continuidade da ação de Rômulo ( $5^{\mathrm{a}}$ ); o renascer do dia e o amadurecimento da romã ( $6^{\underline{a}}$ ); a explosão das sementes da romã ( $7^{a}$ ) e a continuidade da ação de Rômulo ( $8^{\underline{a}}$ ).

Percebe-se uma sequência temporal na cena narrada no poema. A ação se passa no tempo presente e convida o leitor a imaginar o cenário que se apresenta à sua frente, tal como um quadro a ser apreciado. Evidencia-se a sinestesia provocada pelo som do rio que murmura, a cor da romã rubra, o céu, que sugere em dois momentos a escuridão da madrugada e a claridade da manhã.

A economia vocabular, a seleção e a combinação de palavras organizadas em versos curtos, a ausência de conectivos ligando uma ideia a outra marcam a antidiscursividade característica do gênero lírico.

Num nível mais profundo, depois da análise e da compreensão do poema, cabe investigar as possíveis tensões presentes entre a natureza e seu ritmo de espera e a ação do homem que não respeita a natureza que ainda dorme, como se observa nos versos: " O remo abre o rio". "O rio murmura".

Note-se que todos os elementos que foram pontuados no momento inicial da oficina estão contemplados nesse poema: o ritmo, as rimas, a musicalidade, o sensorialismo, a antidiscursividade, a ilogicidade e o ludismo da linguagem.

\section{Oficina de Produção Textual}

Depois da sensibilização do primeiro momento, do estímulo com a recriação a partir de um poema e da análise dos recursos estilísticos de outro poema, o participante já se encontra mais familiarizado com o gênero. É o momento da criação. O tema escolhido é o rio, aproveitando a análise do poema realizada anteriormente.

Selecionamos o poema Rio na sombra da mesma autora que apresenta o rio sob um outro ponto de vista, uma nova perspectiva que será facilmente percebida pelos participantes no decorrer da leitura:

RIO NA SOMBRA
Som
frio.
Rio
sombrio.
O longo som
do rio
frio.
O frio
bom
do longo rio.
Tão longe,
tão bom,
tão frio
o claro som
do rio
sombrio! (MEIRELES, 1990, p. 18)


Inicia-se com a leitura oral compartilhada, ressaltando a entonação, a pontuação, a escolha vocabular, a repetição de fonemas, a presença da nasalidade que percorre o poema, provocando efeitos de sentidos, a economia vocabular, os versos curtos que imprimem o ritmo e as demais características já assinaladas na análise anterior. Não é momento de aprofundar a análise, o objetivo agora é estimular a produção textual que será realizada em seguida.

Inicialmente compare os dois poemas junto com os participantes, levando em consideração: o tema, o tom do discurso, o ritmo, a escolha vocabular, a distribuição das palavras nos versos, a estrutura visual do poema, ou seja, a organização no espaço da folha e o movimento de vai e vem resultante dessa organização que relembra o percurso do rio.

Os dois poemas de Cecília Meireles tratam do mesmo tema, mas sob perspectivas distintas. No primeiro, a autora retrata um rio iluminado pela manhã, com fruto maduro, navegado pelo homem. Já no segundo, pela escolha vocabular, percebe-se um rio longo, frio e sombrio. E o rio de cada participante como seria? Peça-lhes que imaginem um rio e o ambiente em que ele se encontra. Para facilitar a atividade de criação, vale perguntar: Como é o seu rio? O que você vê em volta dele?

É interessante listar as diferentes respostas dos participantes no quadro. De um lado, escreva os substantivos, como por exemplo: margem, capim, flores, barco, água, criança, homem, anzol, peixe, pedras, barro etc Em seguida, acrescente ao lado de cada substantivo um adjetivo ou advérbio que o qualifique. Por exemplo: margens/coloridas; capim/transparente; flores/tristes; barco/apressado; água/iluminada; criança/alegre etc. $O$ objetivo é estimular os participantes a formarem pares de palavras e metáforas que poderão ser aproveitadas no momento da criação individual dos poemas. Essa atividade favorece principalmente àqueles com maior dificuldade de produzir textos, principalmente poemas.

Depois desse "aquecimento" inicial do processo de criação, é hora de cada um criar o seu próprio poema sobre o tema $\mathrm{O}$ rio. Vale aproveitar as imagens criadas em grupo, acrescentar outras, lembrando das características típicas do gênero trabalhadas ao longo do processo.

Após a criação do poema, pode-se ilustrá-lo. Em uma folha de papel, solicitar que desenhem o rio retratado no poema. Nas oficinas ministradas aos estudantes da educação básica, o poema pode ser escrito em uma folha de papel celofane transparente, um pouco maior que a folha do desenho, de maneira que sobre uma borda para ser colada na borda superior atrás do desenho. Depois se escreve o poema sobre o celofane, de forma que, ao se levantar o celofane, o desenho apareça com mais nitidez. O resultado final sempre agrada não só aos mais jovens, mas também aos adultos que vivenciaram essas atividades.

Para concluir, pede-se aos participantes que completem novamente a frase Poesia é.. Peça-lhes que comparem as definições dadas no início e no final do processo e analisem as diferenças em relação ao conceito que tinham inicialmente sobre poesia.

\section{Conclusões}

As opiniões, ao final das oficinas realizadas com diferentes públicos, da educação básica à pósgraduação, confirmam que o caminho para se chegar ao aprendizado depende muito mais de atitudes do que de regras, modelos e reflexões teóricas. O prazer do aprendizado leva à construção de saberes. Comungamos com Moisés (2012, p.14), ao afirmar que, "O verdadeiro conhecimento da poesia pede que nos dediquemos a ela por prazer e não por obrigação. E pede também que não se perca de vista o sentido lúdico, o sentido de jogo e brincadeira que o lidar com palavras pode implicar".

O trabalho com a língua, ao manipular as palavras a partir de um poema dado no momento da recriação, o jogo da linguagem experimentado na etapa da criação de pares de palavras que formam metáforas e a análise e a compreensão de poemas contribuem para que aquele saber empírico ou préconceitual se converta em um saber construído 
coletivamente. $\mathrm{O}$ ensino de língua materna pode ser lúdico, com atividades que gerem a formação de conceitos que possam ser internalizados e não decorados.

A prática da leitura oral compartilhada de poemas, os comentários na tentativa de descobrir os diferentes significados resultantes da seleção e da combinação das palavras, os mecanismos da língua acionados pelo poeta para a construção de imagens, o jogo de subentendidos, as nuances e as ambiguidades vão sendo vivenciados ao longo do processo. Cada poema merece uma abordagem específica, não há pressupostos rígidos e os comentários e análises, por mais minuciosos, serão sempre parciais e relativos. Por isso, essas propostas de atividades são abertas, apontam caminhos, veredas que vão se abrindo à medida que o trabalho com a poesia vai se desenvolvendo.

Certamente há muitas abordagens para o trabalho com a poesia. O importante é instigar o leitor, desinstalando-o do seu lugar de conforto, convidandoo a se aventurar no exercício da leitura e da produção de poemas, desafiando a sua sensibilidade e gerando o prazer estético.

\section{Referências}

A, Tavares Louro. A etimologia de Ofício e de oficina. Ciberdúvidas da Língua Portuguesa. Disponível em: < https://ciberduvidas.iscteiul.pt/consultorio/perguntas/a-etimologia-de-oficio-ede-oficina/15336 > Acesso em: 20 mar. 2020.

BANDEIRA, Manuel. Trem de ferro. São Paulo: Global, 2004.

BILAC, Olavo. Poesias. 2 ed. São Paulo: Martins Fontes, 2001.

CARA, Salete de Almeida. A poesia lírica. São Paulo: Ática, 1986, 2ed. (Col. Princípios, 20)

CANDIDO. Antonio. Na sala de aula. 2 ed. São Paulo: Ática, 1986. (Série Fundamentos).

CÍCERO Antônio. Letra de canção e poesia. Folha de São Paulo llustrada. São Paulo, 16 jun. 2007.

Disponível em:

<https://www1.folha.uol.com.br/fsp/ilustrad/fq1606200 734.htm>. Acesso em: 26 mar. 2020.

MEIRELES, Cecília. Ou isto ou aquilo. Rio de Janeiro: Nova Fronteira, 8 ed. 1990.
MOISÉS, Carlos Felipe. Poesia não é difícil. São Paulo, Biruta, 2012.

MORICONI, Ítalo. Como e por que ler a poesia brasileira do século XX. Rio de Janeiro: Objetiva, 2002. QUINTANA, Mário. Nariz de vidro. São Paulo: Moderna, 2 ed., 2003.

SOARES, Angélica. Gêneros literários. São Paulo: Ática, 1989, 2ed. (Col. Princípios, 166)

\section{COMO CITAR ESSE ARTIGO}

RICHE, Rosa Maria Cuba. Nas malhas da poesia: oficina de leitura e criação; In meshes of poetry: workshop of reading and creation. Signo, Santa Cruz do Sul, v. 45, n. 83, set. 2020. ISSN 1982-2014. Disponível em: <https://online.unisc.br/seer/index.php/signo/article/view/14959> . Acesso em: doi:https://doi.org/10.17058/signo.v45i83.14959. 